Mariana Pires Luz ${ }^{1}$

(1) https://orcid.org/0000-0002-0297-5245

William Berger?

Ohttps://orcid.org/0000-0001-7656-4548

\title{
COVID-19 pandemics and mental health: In times like these, we learn to live again
}

DOl: $10.1590 / 0047-2085000000273$

The scenario of pandemics is one of the most dreaded and alarming by mankind. Unfortunately, this is the scenario we are facing now. During a period of pandemics, many situations can be overwhelming, not only related directly to the primary disease, but also related to the measures needed to be taken to combat it, and also its aftermath.

Pandemic-related stressors may come in many ways. Uncertainty and anticipated fear, excessive (and possibly fake or misguided) information, psychological and social distress, fear of death or serious illness, loss of close ones, economical societal burden and personal financial difficulties are only a few examples of stressful situations that come along with the pandemics ${ }^{1,2}$. Considering the prolonged and sustained nature of a pandemic, encompassing exposure to multiple potentially traumatic events during a significant period, it could be considered a type of complex trauma ${ }^{3-5}$.

History has already shown that psychiatric morbidity is another dreadful outcome from an epidemic. The SARS (severe acute respiratory syndrome) epidemic in 2003 victimized more than 700 individuals, mostly in Asian countries. Up to 45\% of SARS survivors that needed hospitalization had at least one psychiatric diagnosis in the immediate discharge from the hospital, including depression, anxiety disorders, and posttraumatic stress disorder (PTSD) symptoms. Even long term pos-discharge evaluations (e.g. 30 months after discharge) showed persistent psychiatric morbidity among SARS patients, mainly PTSD, depressive disorders and anxiety-spectrum disorders ${ }^{6,7}$. After the 2014/2015 Ebola virus outbreak in Africa, many psychiatric and Psychosocial problems arose, such as stigma and isolation, and also psychiatric disorders in the general population and among health care workers, including PTSD, depression and anxiety disorders ${ }^{8,9}$. The Middle East Respiratory Syndrome (MERS) in 2015, which had a high mortality rate (about 20\%) caused hundreds of people - and entire villages and cities - to be intensively isolated. During the period of isolation due to the MERS epidemic, more than $40 \%$ of the general population reported emotional distress. Among patients, almost $50 \%$ reported significant symptoms of anxiety ${ }^{10}$. It is to be expected that the COVID-19 pandemics will have several psychiatric short- and long-term consequences as well.

COVID-19 pandemics is triggering psychological distress and psychiatric problems. Individual characteristics such as culture, economic status, coping mechanisms, previous psychiatric or psychological issues, personal degree of exposure to the risk of contamination, actual development of the disease and/or loss of close persons are some of the factors that influence psychological response to such unusual and uncertain times. In a societal level, access to accurate and legitimate information, availability of medical services, governmental and medical measures to contain the spread of infection (e.g. quarantine and social isolation) and general psychosocial condition of the community may influence the collective response to the outbreak $k^{9,11-13}$.

But not all is bad. Human resilience is a powerful force, and it sometimes can overcome the hardest of problems. The majority of the population will present healthy mental health responses to the traumatic events experienced during the pandemic. Peoples' ability to 
cope, to endure, to recover and to rebuild can even be strengthened in such difficult times. Some individuals may report increased feelings of gratitude, greater appreciation for friends and family, increased care for mental and physical health, stronger beliefs and faith, and even a sense of personal growth 11,14,15.

Recommendations for a better mental health outcome include strategies to enhance individual and collective resilience, intense psychiatric surveillance in individual and community levels, and identification and referral of individuals ate greater risk for development and intensification of psychiatric disorders. Providing accurate and reliable information to the population about the disease and the measures taken to combat it, promoting access to quality health care services, and implementing social and financial aid to the most needed are key features to prevent psychiatric morbidity. Also, combating stigmatization and social isolation of those who had the disease or lost someone close to it, stimulation of initiating and maintaining adequate psychiatric and psychological treatments, and implementing strong psychosocial interventions are key factors for enhancing the chances of a healthy psychiatric response from the COVID-19 pandemic 1,4,16,17. Finally, quoting Ali Ibn Abi Talib, the supposed cousin and son-in-law of Muhammad, "Do not let your difficulties fill you with anxiety, after all it is only in the darkest nights that stars shine more brightly"18.

\section{REFERENCES}

1. Perrin PC, McCabe OL, Everly GS, Links JM. Preparing for an influenza pandemic: mental health considerations. Prehosp Disaster Med. 2009;24(3):223-30.

2. Taylor S. The Psychology of Pandemics: Preparing for the Next Global Outbreak of Infectious Disease. Newcastle upon Tyn: Cambridge Scholars Publishing; 2019.
3. Maercker A, Brewin CR, Bryant RA, Cloitre M, van Ommeren M, Jones LM, et al. Diagnosis and classification of disorders specifically associated with stress: proposals for ICD-11. World Psychiatry. 2013;12(3):198-206.

4. Bao Y, Sun Y, Meng S, Shi J, Lu L. 2019-nCoV epidemic: address mental health care to empower society. Lancet. 2020;395(10224):e37-8.

5. World Health Organization (WHO). International statistical classification of diseases and related health problems. 11th ed. Geneva: WHO; 2019

6. Mak IWC, Chu CM, Pan PC, Yiu MGC, Chan VL. Long-term psychiatric morbidities among SARS survivors. Gen Hospl Psychiatry. 2009;31(4):318-26.

7. Tucci V, Moukaddam N, Meadows J, Shah S, Galwankar SC, Kapur GB. The forgotten plague: Psychiatric manifestations of Ebola, Zika, and emerging infectious diseases. J Glob Infect Dis. 2017;9(4):151-6.

8. Mohammed A, Sheikh TL, Poggensee G, Nguku P, Olayinka A, Ohuabunwo C, et al. Mental health in emergency response: lessons from Ebola. Lancet Psychiatry. 2015;2(11):955-7.

9. Shultz JM, Baingana F, Neria Y. The 2014 Ebola outbreak and mental health: current status and recommended response. JAMA. 2015;313(6):567-8.

10. Jeong H, Yim HW, Song YJ, Ki M, Min JA, Cho J, et al. Mental health status of people isolated due to Middle East Respiratory Syndrome. Epidemiol Health. 2016;38:e2016048.

11. Liu D, Ren Y, Yan F, Li Y, Xu X, Yu X, et al. Psychological Impact and Predisposing Factors of the Coronavirus Disease 2019 (COVID-19) Pandemic on General Public in China. 2020. Available at: https://ssrn.com/abstract=3551415.

12. Liu N, Zhang F, Wei C, Jia Y, Shang Z, Sun L, et al. Prevalence and predictors of PTSS during COVID-19 Outbreak in China Hardest-hit Areas: Gender differences matter. Psychiatry Res. 2020;287:112921.

13. Thurackal BJ, Chith EN, Mascarenhas P. The Outbreak of Novel Coronavirus in India: PsychoIogical Impact. Available at: https://ssrn.com/abstract=3562062.

14. Greenberg N, Docherty M, Gnanapragasam S, Wessely S. Managing mental health challenges faced by healthcare workers during covid-19 pandemic. BMJ. 2020;368:m1211.

15. Paladino L, Sharpe RP, Galwankar SC, Sholevar F, Marchionni C, Papadimos TJ, et al. Reflections on the Ebola public health emergency of international concern, part 2: the unseen epidemic of posttraumatic stress among health-care personnel and survivors of the 20142016 Ebola outbreak. J Glob Infect Dis. 2017;9(2):45-50.

16. $\mathrm{H}_{0} \mathrm{C}$, Chee C, Ho R. Mental Health Strategies to Combat the Psychological Impact of COVID-19 Beyond Paranoia and Panic. Ann Acad Med Singapore. 2020;49(3):155-60.

17. World Health Organization (WHO). Mental health and psychosocial considerations during the COVID-19 outbreak, 18 March 2020. Geneva: WHO; 2020.

18. Poonawala K., "'ALĪ B. ABĪ TṬĀLEB I. Life," Encyclopaedia Iranica, Online Edition, 1982. Available at: http://www.iranicaonline.org/articles/ali-b-abi-taleb\#pt1. 